\title{
Síndrome de Asperger: flexibilidad cognitiva, teoría de la mente, y lenguaje expresivo y comprensivo. Aportaciones al perfil neuropsicológico
}

\section{Asperger Syndrome: cognitive flexibility, theory of mind, and expressive language and understanding. Contributions to the neuropsychological profile}

\author{
Angélica María González-Martínez (D) \\ $\triangle$ angelicagm12@gmail.com \\ Universidad de Manizales, Caldas, Colombia \\ Luisa María Yela-Torres (D) \\ \luisa maria y@hotmail.com \\ Universidad de Manizales, Caldas, Colombia \\ Juan Bernardo Zuluaga-Valencia (D) \\ $\triangle$ juanb@umanizales.edu.co \\ Universidad de Manizales, Caldas, Colombia
}

Recibido: $12-04-2018$

Aceptado: 28-05-2018

Publicado: 01-06-2018

\section{RESUMEN}

Objetivo. caracterizar el desempeño neuropsicológico en flexibilidad cognitiva, ToM, lenguaje comprensivo y expresivo en niños diagnosticados con Síndrome de Asperger. Método. estudio de tipo no experimental de carácter descriptivo, con veinte sujetos diagnosticados con SA entre los seis y dieciséis años de edad de la ciudad de Manizales (Colombia). Los instrumentos utilizados para evaluar la flexibilidad cognitiva, la ToM y el lenguaje comprensivo y expresivo han sido el subtest de flexibilidad cognoscitiva de la Evaluación Neuropsicológica Infantil (ENI), la batería de Baron-Cohen de falsas creencias de primer y segundo orden, las subpruebas de semejanzas, vocabulario y comprensión del WISC-IV y la subprueba de composición narrativa de la ENI. Resultados. Ios niños con SA obtuvieron puntajes promedios inferiores a la norma en todas las variables, sin embargo, los resultados tanto en ToM de segundo orden, flexibilidad cognitiva y lenguaje expresivo tienden a evolucionar de manera positiva en el rango de edad de once a dieciséis años. Conclusiones. se evidencia que independientemente del proceso evolutivo, continúa permaneciendo la dificultad en el desempeño de lenguaje comprensivo y falsas creencias de primer orden en los niños con este trastorno.

Palabras clave: Síndrome de Asperger; flexibilidad cognitiva; teoría de la mente; falsas creencias; lenguaje comprensivo; lenguaje expresivo. 


\section{ABSTRACT}

Objective. to characterize neuropsychological performance in cognitive flexibility, ToM, and expressive language in children diagnosed with Asperger's Syndrome. Methods. non-experimental type study of comparative descriptive character, with 20 subjects diagnosed with Asperger syndrome between 6 and 16 years of age in the city of Manizales (Colombia). The instruments used to evaluate cognitive flexibility, ToM and expressive and comprehensive language have been the subtest of cognitive flexibility of the Infant Neuropsychological Evaluation (ENI); Baron-Cohen's battery of false first- and secondorder beliefs, similar subtests, vocabulary and comprehension of the WISC-IV and the narrative composition subtest of the ENI. Results. Children with SA obtained lower average scores than the standards in all variables. However, the results in second-order ToM, cognitive flexibility and expressive language tend to increase in the age range of 11 to 16 years. Conclusions. It becomes evident that regardless of the evolutionary process, the difficulty of comprehensive language performance and the false beliefs of first order in children with this disorder remains.

Keywords: Asperger syndrome; cognitive flexibility; theory of mind; false beliefs; sympathetic language; expressive language.

\section{INTRODUCCIÓN}

De acuerdo a la revisión de antecedente se hace evidente que la población de niños diagnosticados con SA ha sido poco estudiada en Colombia. Según el Ministerio de Salud y protección social (2015) "Se estima que aproximadamente un $16 \%$ de la población menor de 15 años en Colombia padece algún tipo de trastorno del desarrollo, entre ellos los trastornos del espectro autista (TEA); sin embargo, Colombia no cuenta con cifras oficiales que establezcan la prevalencia en el país de este trastorno." De acuerdo con el Sistema Integral de Información de la Protección Social (SISPRO), en el año 2013 se registraron 45 personas con diagnóstico de Asperger (citado en Ministerio de Salud y protección social, 2015). A la fecha no hay registros actualizados en Colombia relacionados con esta población. El Instituto para el Desarrollo Integral del Niño Autista (DINA), de la Universidad de Manizales, institución con la que se contó para realizar el presente estudio, atiende una población de 35 niños y niñas con dicho diagnóstico. Lo que deja claro que, en cuanto a porcentaje, existe un subregistro en el país.

Entre las dificultades que presentan los niños con SA se encuentran las relacionadas con su desempeño escolar, social y comportamental; dificultades que están estrechamente vinculadas con las funciones ejecutivas, teoría de la mente y lenguaje.

Este trastorno fue descrito por Hans Asperger en 1944 (Asperger, 1944), incluido en el DSM-IV (American Psychiatric Association, 2002) dentro de los trastornos generalizados del desarrollo y en el DSM-V (Manual diagnóstico y estadístico de los trastornos mentales: DSM-5, 2014.) posteriormente, como un trastorno del espectro autista, caracterizado por una alteración cualitativa en la interacción social, en la comunicación y un repertorio de interés y actividades restringido, estereotipado y repetitivo. 
En el DSM-V (Asociación Americana de Psiquiatría, 2013) se valoran únicamente dos criterios sintomáticos, si bien el primero incorpora dos de los presentes en el DSM-IV$T R$, se hace referencia concretamente a las alteraciones persistentes en la comunicación y la interacción social, y a un patrón de comportamientos, intereses o actividades restringidas y repetitivas.

Cabe anotar que en el SA se presentan alteraciones de manera heterogénea con relación al lenguaje. "[...] pueden llegar a poseer un lenguaje que se manifiesta superficialmente correcto y conservado en sus aspectos formales, pero alterado en su vertiente pragmática y en el uso de elementos contextuales del lenguaje turnos de palabra, inicios de conversación, lenguaje figurado y clarificador [...]" (Artigas, 2000). Los mismos autores aseguran que la inteligencia de las personas con este diagnóstico aparenta ser normal y pueden tener habilidades especiales para funciones como la memoria o un interés exagerado hacia temas como las matemáticas o las ciencias, o para otras áreas intelectuales específicas. Pero con grandes limitaciones a la hora de interactuar o compartir dichos conocimientos.

Por otro lado, según la literatura, se encontró, que los niños con mejores habilidades lingüísticas y sociales tienen mejor desempeño en lo que respecta a la lectura de estados mentales de otras personas (Paynter y Peterson, 2010)19 with high-functioning autism, and 20 age-matched typical developers. Serrano (2012) y Van Eylen et al. (2011) postulan que las funciones ejecutivas se encuentran detrás del crecimiento simultáneo de las habilidades lingüísticas y mentalistas en los niños durante la infancia. Este factor común ha sido pieza central de investigaciones que lo asociaban con la flexibilidad cognitiva (Serrano, 2012; Van Eylen et al., 2011), función ejecutiva que se aborda en el presente estudio. Lo anterior permite resaltar la importancia de continuar con estudios frente a estas variables de manera integrada en el SA.

Por consiguiente, se considera importante el desarrollo del presente artículo, no solamente en su aporte a la consolidación del conocimiento de este trastorno, sino que dichos hallazgos son un aporte a los profesionales del instituto DINA para la generación de posibles rutas de intervención y también con la expectativa de generar una visibilización del trastorno en la sociedad y en las instituciones educativas, como una apuesta a los procesos de inclusión.

\section{Variables estudiadas:}

Teoría de la mente. El concepto de teoría de la mente nace en la etología con Premack y Woodruf (1978) con los estudios sobre chimpancés, en los que la definen como el acto de tratar de inferir y conceptualizar sobre los estados mentales y emocionales. Sin embargo, a partir de los estudios de autores como Wimmer y Perner(1983) (Citados por Frith, 2004), se aplicaron a estudios sobre el desarrollo del niño (Wellman, Cross y Watson, 2001), igualmente Baron-Cohen, Leslie y Frith (1985) lo aplicaron al estudio del autismo. Por su parte, Corcoran (1996) lo estudiaron en pacientes con esquizofrenia.

El estudio de la teoría de la mente pasó a ser un campo de interés para la psicología del desarrollo y en la actualidad es de utilidad para la neuropsicología y la neurociencia cognitiva (Grande-García, 2012). Baron-Cohen (2000) y Leslie (1987) han centrado sus investigaciones en el autismo. Según ellos, "estos niños tienen graves problemas para 
teorizar acerca de la mente de los demás, y además afirman que la forma menos grave del autismo se denomina síndrome de Asperger".

Por su parte, Tirapu-Ustárroz, Pérez-Sayes, Erekatxo-Bilbao y Pelegrín-Valero (2007) definen que "el concepto de ToM se refiere entonces a la habilidad para comprender y predecir la conducta de otras personas, sus conocimientos, sus intenciones y sus creencias". Dentro de todo esto se refieren aspectos metacognitivos como las mentiras - la ironía, la capacidad de interpretar emociones básicas y sociales como la empatía, captar el discurso metafórico o la cognición social (Tirapu-Ustárroz et al., 2007).

Para explicar la teoría de la mente desde un plano neurobiológico, Siegal y Varley (2002) describen "que las áreas implicadas en la teoría de la mente están relacionadas con lenguaje, funciones ejecutivas y emociones, y presentan múltiples áreas de coactivación: corteza temporal y lóbulo frontal; hemisferio derecho, STS, corteza parietal inferior y circuitería de amígdala" (véase también Brunet Sarfati, Hardy-Bayle y Decety, 2000; Yogeley, 2001; Siegal y Varley, 2002, citado en Ibáñez, 2005).

De acuerdo a lo anterior, las estructuras mencionadas tienen relación con las propuestas por Tirapu-Ustárroz et al. (2007), en la que plantean que en la amígdala y corteza frontal dorsolateral se relacionan las tareas de creencias de primer y segundo orden.

Para Tirapu-Ustárroz et al. (2007), estas habilidades metacognitivas más complejas (funciones cognitivas) emergen con la maduración cerebral fruto del desarrollo individual por medio de la experiencial a través del cual un sujeto logra una representación de sí mismo refiriéndose a la autoconciencia y de los demás, tal que se llega así a la teorización de la mente, entendido esto como meta representaciones (Delgado y Etchepareborda, 2013). El mismo autor propone una organización de la ToM y de los contenidos y sus estructuras cerebrales. Aclara además que la ToM parte desde lo más simple hasta lo complejo, iniciando con reconocimiento facial, creencia de primer y segundo orden, utilización social del lenguaje (ironía, mentiras), comportamiento social (meteduras de pata) y finalizando con cognición social y empatía (Tirapu-Ustárroz et al., 2007).

De ahí se concluye que la teoría de la mente está vinculada con la comprensión de los estados mentales, la inteligencia emocional y social, la atención compartida y la capacidad de meta representación, y que al final es lo que lleva a comprender las intenciones y pensamientos de los demás. Los niños con Trastorno del Espectro Autista (TEA) tienen también grandes dificultades para diferenciar aquello que es verdad de lo que es mentira y es por esto que les resulta muy complicado entender las ironías o captar el doble sentido de algunas frases, debido a que tienen muy poca flexibilidad mental (Cornago, Navarro y Collado, 2012).

Las investigaciones que se han dedicado al estudio de la teoría de la mente sugieren que las habilidades mentalistas no se dan de manera automática en niños pequeños, los cuales deben desarrollar una serie de habilidades para desenvolverse en un nivel de competencia adulto, por tanto, necesita de unos precursores que permitan el desarrollo de dicha capacidad. Precursores tales como la atención y las múltiples propiedades del lenguaje. En concreto la evidencia empírica recogida hasta la fecha señala las capacidades lingüísticas como claves para entender el desarrollo de habilidades mentalistas, particularmente en la comprensión de la tarea de falsa creencia (Milligan, Astington y Dack, 2007, citado en Resches, Serrat, Rostan y Esteban, 2010). 
Flexibilidad cognitiva. De acuerdo a Martos-Pérez y Paula-Pérez (2011), la flexibilidad cognitiva, también denominada "cambio de criterio", es la habilidad para cambiar a un pensamiento o acción diferente en función de los cambios que ocurren en las situaciones o contextos. Además, agrega factores como la rigidez e inflexibilidad cognitiva y conductual, la insistencia en la invarianza ambiental, los rituales y rutinas, las ecolalias tan propias de la sintomatología de los TEA son los indicadores conductuales que están estrechamente relacionados con las funciones ejecutivas.

Lezak (1982) describe que las funciones ejecutivas son reguladoras del comportamiento humano, permiten planificar y formular metas y facilitan el control y la organización de otras funciones cognitivas. Es así como este autor concibe las funciones ejecutivas como funciones reguladoras del comportamiento humano, necesarias para formular metas, planificar la manera de lograrlas y llevar adelante el plan de manera eficaz. En la misma línea, Duncan, Burgess y Emslie (1995) las describen como "las habilidades necesarias para mantener un conjunto de estrategias de soluciones de problemas, con el fin de alcanzar una meta". Es claro que los niños con este diagnóstico suelen tener dificultades para la resolución de problemas o con la planificación y organización de procesos para llegar a una meta, esto estrechamente relacionado con las funciones ejecutivas y más específicamente la flexibilidad cognitiva.

Una alteración importante de las funciones ejecutivas en el SA es la dificultad para generar objetivos y metas adecuadas para crear nuevos comportamientos; en este caso, la alteración en la creatividad, la espontaneidad y la flexibilidad lleva a una repetición continua de la conducta o a un empleo estereotipado de los objetos, juegos y a la dificultad para adaptarse a los entornos (Soprano, 2003). Tales aclaraciones llevan a relacionar estas deficiencias identificadas en el diagnóstico de SA en cuanto a funciones mentales superiores se trata.

Como complemento a las teorías anteriores, Riviére (2001) el hecho de que hablar (o no hablar describe que desde edades tempranas (dos a cinco años), se construyen las funciones superiores, lo que nutre el conocimiento y la experiencia. En estas etapas se desarrollan principalmente el lenguaje, la simbolización, las habilidades sociales y las capacidades mentalistas. En poco tiempo surge la flexibilidad que finalmente se convierte en adaptación, imaginación y creación (citado en Valdez y Huertas, 2005). Es por esto que en la presente investigación se retoman dos grupos de edades en las que se pretende evidenciar la evolución madurativa presentada por Riviére (2001).

En un estudio de Semrud-Clikeman, Walkowiak, Wilkinson y Butcher (2010), se plantea que los niños con SA comparten los síntomas de inatención, impulsividad e hiperactividad con niños diagnosticados con trastorno de déficit de atención e hiperactividad (TDAH) y que estos síntomas se relacionan con la inflexibilidad mental y desorganización para la resolución de problemas y adaptación de acuerdo a las demandas ambientales. Desde este estudio, las alteraciones abarcan el funcionamiento ejecutivo general, sin embargo, para el caso del SA se destaca la alteración en flexibilidad cognitiva específicamente. "Se encontraron además dificultades en el control e inhibición emocional, automonitoreo, flexibilidad cognitiva, planeación, organización y fluidez verbal." (Semrud-Clikeman et al. 2010). Estos hallazgos, junto con otras observaciones como las de Van Eylen et al. (2011), indican que las personas con TEA tienen impedimentos de flexibilidad cognitiva. 
Lenguaje. Bloom, Lahey, Hood, Lifter y Fiess (1980) definen el lenguaje como un código de comunicación en el que por medio de un sistema de signos se representan las ideas del mundo. Describen además que el uso del lenguaje es un acto social y el niño lo aprende como herramienta para obtener, mantener y regular el contacto con otras personas (citado en Barragán y Lozano, 2011)

A lo largo del tiempo, filósofos, lingüistas y psicólogos concluyeron que el lenguaje es un sistema complejo que puede analizarse en función de su fonología (sistemas de sonidos), morfología (reglas para formar palabras), léxico (vocabulario) sintaxis (reglas para formar oraciones), semántica (significado de las palabras y oraciones) y pragmática (reglas para utilizar el lenguaje adecuado en contextos sociales) (Berko y Bernstein, 1999, citado en Carmona, 2001).

Existen descripciones de características documentadas de las personas con SA en las que se especifican las alteraciones en el lenguaje comprensivo y expresivo; una de ellas es la planteada por Riviére (2002), en la que se menciona los trastornos cualitativos del lenguaje receptivo y se presentan dificultades en asignar significados a expresiones figuradas, así como carencia de diferenciación de las intenciones; para dichos trastornos del lenguaje expresivo, se presentan dificultades para intercambiar roles y turnos conversacionales, suelen darse cambios abruptos de tema, hay tendencia hacia temas irrelevantes e inapropiados y un uso de lenguaje pedante o rebuscado (Riviére, 2002). Para Frontera-Sancho (2010), las personas con SA tienden a adquirir un desarrollo normal o avanzado para la lectura mecánica o decodificación de palabras. Sin embargo, muestran dificultad a la hora de responder a preguntas abiertas. La comprensión del texto de las personas con SA es superficial y en ocasiones muy literal.

Por otro lado, Martín-Borreguero, (2005) describe la gran capacidad de la persona con diagnóstico de SA para conocer el significado de palabras inusuales, así como su torpeza para definir y usar términos comunes y coloquiales, es por esto que para ellos no solo basta con leer, sino con indagar más acerca de lo que leen.

"La persona con SA asigna significados fijos a las palabras basados en percepciones concretas y experiencias específicas. Su rigidez cognitiva le impide aceptar otros significados diferentes para las mismas palabras en función al contexto social" (Martín-Borreguero, 2005). Se observa aquí gran relación entre el lenguaje y la flexibilidad cognitiva, en el momento de dar cambio o un sentido de acuerdo al lenguaje simbólico o a las exigencias y adaptaciones del contexto (Ozonoff y Miller, 1996). En relación a lo planteado por Martín-Borreguero (2005), se evidencia que en el perfil de las habilidades y déficit semánticos asociados al SA, presentan un desarrollo adecuado o avanzado del léxico receptivo y expresivo con respecto a la edad cronológica, una adquisición de un vocabulario sofisticado y complejo, con una capacidad adecuada de comprensión de conceptos concretos y formación de categorías; pero a pesar de estas competencias presentan déficit en la comprensión de las relaciones semánticas de temporalidad y espacialidad en el tiempo, al igual que de conceptos abstractos, dificultades en el procesamiento del lenguaje figurativo, metafórico y en la realización de inferencias, giros lingüísticos y formas verbales, sarcásticas e irónicas (Martín-Borreguero, 2005). Este autor define que en términos del procesamiento semántico ha sido demostrado que los adolescentes y adultos con TEA tienen un patrón atípico, en el cual no solo se les dificulta la comprensión de estados mentales, metáforas y aspectos socio-pragmáticos del lenguaje, sino que se extiende a tareas que involucran la memoria. 
Saalasti et al. (2008) concluyeron que los déficits encontrados posiblemente se deben a que los individuos con SA se centran en los detalles dejando de integrar la información de forma coherente y focalizando su atención en una sola palabra, lo cual lleva a la incomprensión de la totalidad de la frase (Citado por Beltrán, Díaz y Zapata, 2016).

En este orden de ideas, cabe anotar que por medio del desarrollo del lenguaje semántico se adquiere un adecuado lenguaje comprensivo, lo que nos lleva a entender que la comprensión del lenguaje constituye un proceso cognitivo de construcción del significado, en el que se debe poner en marcha estrategias comunicativas, como reconocer, seleccionar, inferir, anticipar y retener, para poder interpretar un mensaje (Cassany, Luna y Sanz, 1994, citado en Camila, 2008). Por consiguiente, "requiere de un conocimiento no solo de las formas y estructuras de la lengua utilizada en la construcción del texto, sino, además, de la relación entre el texto, el contexto y la situación comunicativa concreta" (Gómez y Peronard, 2005, citado en Camila, 2008).

\section{MÉTODO}

Tipo de investigación. La investigación es de tipo no experimental, de carácter descriptivo comparativo entre rangos de edad.

Población y muestra. La muestra está conformada por veinte participantes diagnosticados con SA entre los seis y dieciséis años que asisten a proceso terapéutico al instituto Instituto para el Desarrollo Integral del Niño con Autismo (DINA) de la ciudad de Manizales. Los participantes fueron separados en dos grupos: el primero entre los seis y diez años y el segundo entre los once y dieciséis años.

La elección de los participantes se hizo de manera intencional a través de la base de datos del instituto DINA, seleccionando a aquellos participantes que estuvieran en este rango de edades, que tuvieran diagnóstico de SA con un cociente intelectual (CI) superior a 85 y estuvieran escolarizados. Fueron evaluados previamente por un grupo interdisciplinar conformado por neuropsicólogos, psiquiatras y psicólogos entre los años 2013 y 2014, valorados en su momento con el DSM-IV-TR (American Psychiatric Association, 2002), el cual incluía el SA. Sin embargo, este diagnóstico, según el DSM-V (Asociación Americana de Psiquiatría, 2013), se denomina en la actualidad "trastorno de espectro autista". Todos los padres de los participantes firmaron un consentimiento para el estudio.

Instrumentos. La obtención de datos se efectuó mediante la aplicación de la adaptación abreviada del WISC III, adaptada por Sattler (2003) forma C6 x2: subescalas de vocabulario y diseño con cubos.

- Para CI como criterio de inclusión, el test de falsas creencias de primer y segundo orden (test de Sally y Anne) (Baron-Cohen, Leslie y Frith.,1985)

- Para la medición de teoría de la mente, la subprueba de la Evaluación Neuropsicológica Infantil (ENI) (Rosselli et al., 2004), versión adaptada del Test de clasificación de cartas de Wisconsin (WCST).

- Para medir flexibilidad cognitiva, las subpruebas de comprensión, semejanzas e información del WISC-IV (Wechsler, 2005). 
- Para la evaluación del lenguaje comprensivo, la subprueba de composición narrativa coherencia narrativa de la ENI (Rosselli et al., 2004), para lenguaje expresivo.

\section{Procedimiento}

Fase I: se seleccionaron los participantes con diagnóstico de SA del Instituto DINA.

Fase II: aplicación de instrumentos.

Fase III: análisis de la información. Los resultados se analizaron estadísticamente mediante el software de procesamiento estadístico SPSS versión 21. Para evaluar las diferencias entre las variables, se aplicó la prueba U de Mann-Whitney. Dentro del análisis se consideraron los rangos de edad (seis a diez y once a dieciséis años) y ToM, como variable independiente y los resultados de cada una de las pruebas como variable dependiente.

\section{RESULTADOS}

\section{Descripción general de las pruebas}

En teoría de la mente de primer y segundo orden: los resultados sugieren una menor habilidad en los participantes en general para inferir que alguien tiene una creencia equivocada (primer orden) y una mayor habilidad de atribuir falsas creencias a los demás (segundo orden). Cabe anotar que las relaciones con las demás variables surgen de los resultados obtenidos en ToM, pues al ser de calificación cualitativa, se convierte en variable independiente al igual que el rango de edad.

Análisis por rangos de edad: en ambas pruebas el incremento de la edad favorece su aprobación. Se evalúo si existía dependencia entre las falsas creencias de primer y segundo orden y se determinó que en ninguno de los casos existe tal asociación.

Relación de las pruebas de flexibilidad cognitiva y lenguaje comprensivo y expresivo, por rangos de edad, diferencias porcentuales entre grupos y comparación de medias: en cuanto a flexibilidad cognitiva, los participantes en el rango de once a dieciséis años obtuvieron un puntaje promedio mayor al del grupo de seis a diez años en la prueba de número de categorías, pero un puntaje promedio menor en el número de respuestas perseverativas. Esto sugiere que los participantes en el rango de edad más alto tienen una mayor flexibilidad cognitiva que los de menor edad. No obstante, al comparar las medias no existieron diferencias estadísticamente significativas entre los grupos.

En el lenguaje comprensivo, los participantes en el rango de seis a diez años obtuvieron un puntaje promedio mayor al del grupo de once a dieciséis años en las pruebas de vocabulario y comprensión, pero un puntaje promedio menor en la prueba de semejanzas. En el lenguaje expresivo, los participantes en el rango de seis a diez años obtuvieron un puntaje promedio menor al del grupo de once a dieciséis años en la prueba de coherencia narrativa. No obstante, al comparar las medias en las pruebas de lenguaje no se encontraron diferencias estadísticamente significativas entre los grupos.

Al analizar el desempeño obtenido en lenguaje comprensivo y expresivo ambos grupos tuvieron un desempeño por debajo de la media, y se observaron los desempeños más deficientes en comprensión y coherencia narrativa (Tabla 1). 
Tabla 1. Desempeños más deficientes en comprensión y coherencia narrativa.

\begin{tabular}{|c|c|c|c|c|c|c|c|c|}
\hline \multirow{2}{*}{ Variables } & \multirow{2}{*}{ Prueba } & \multicolumn{2}{|c|}{6 a 10 años } & \multicolumn{2}{|c|}{11 a 16 años } & \multirow{2}{*}{$\begin{array}{c}\text { Diferencia } \\
\text { porcentual entre } \\
\text { grupos }\end{array}$} & \multicolumn{2}{|c|}{ Comparación de medias } \\
\hline & & $\underline{\mathbf{x}}$ & D.S. & $\underline{\mathbf{x}}$ & D.S. & & $\begin{array}{c}\text { Ude } \\
\text { Mann-Whitney }\end{array}$ & Valor $\mathbf{p}$ \\
\hline \multirow{2}{*}{$\begin{array}{l}\text { Flexibilidad } \\
\text { cognitiva }\end{array}$} & $\begin{array}{l}\text { Número de } \\
\text { categorías }\end{array}$ & 1,92 & 1,00 & 2,38 & 1,19 & 19,30 & 35,500 & 0,313 \\
\hline & $\begin{array}{c}\text { respuestas } \\
\text { perseverativas }\end{array}$ & 8,08 & 11,29 & 6,88 & 6,08 & $17,58 *$ & 46,500 & 0,907 \\
\hline \multirow{3}{*}{$\begin{array}{c}\text { Lenguaje } \\
\text { comprensivo }\end{array}$} & Semejanzas & 9,42 & 3,03 & 11,88 & 4,32 & 20,70 & 32,000 & 0,212 \\
\hline & vocabulario & 9,33 & 3,82 & 8,25 & 2,96 & $13,13 *$ & 36,000 & 0,348 \\
\hline & comprensión & 6,17 & 3,54 & 5,50 & 5,24 & $12,12 *$ & 37,500 & 0,415 \\
\hline $\begin{array}{l}\text { Lenguaje } \\
\text { expresivo }\end{array}$ & $\begin{array}{c}\text { Coherencia } \\
\text { Narrativa }\end{array}$ & 5,58 & 3,03 & 7,00 & 1,07 & 20,24 & 38,000 & 0,416 \\
\hline
\end{tabular}

*Valor medio rango seis a diez años > valor medio rango once a dieciséis años.

Fuente: elaboración propia

En la tabla 1 , se presenta el valor medio $(\chi)$ y la desviación estándar (D.S.) en las pruebas de flexibilidad cognitiva y lenguaje comprensivo, por rangos de edad. Adicionalmente se muestra el porcentaje de diferencia entre los grupos y la respectiva comparación entre las medias. Para la elección de la prueba de comparación de medias se verificó la normalidad de los puntajes mediante la prueba de Shapiro-Wilk y se encontró que no todas seguían una distribución normal (valor $p<0,05$ ), motivo por el cual se seleccionó la prueba U de Mann Whitney para efectuar dicha comparación.

Relación entre variables de flexibilidad cognitiva y lenguaje comprensivo, por rangos de edad, respecto a la prueba de falsas creencias de primer orden: los resultados muestran que los participantes en ambos rangos de edad que sí aprobaron la prueba de falsas creencias de primer orden tuvieron un mayor puntaje promedio en el número de categorías y un puntaje promedio menor en el número de respuestas perseverativas, lo que sugiere que quienes sí superan la prueba tienen una mayor flexibilidad cognitiva. En el lenguaje comprensivo, en el rango de seis a diez años, quienes superaron la prueba de falsas creencias de primer orden tuvieron un mayor puntaje promedio en las tres pruebas. Contrariamente, en el grupo de once a dieciséis años, quienes no superaron la prueba de falsas creencias de primer orden, fueron los que obtuvieron un mayor puntaje promedio en las tres pruebas de lenguaje. En el lenguaje expresivo en ambos rangos de edad, quienes superaron la prueba de falsas creencias de primer orden tuvieron un mayor puntaje promedio en la prueba de coherencia narrativa. Posteriormente se evaluó si existían diferencias estadísticamente significativas entre los grupos de edad, entre quienes aprobaron la prueba de falsas creencias de primer orden y quienes no la aprobaron (Tabla 2). 
Tabla 2. Prueba de falsas creencias de primer orden.

\begin{tabular}{|c|c|c|c|c|c|c|c|c|c|}
\hline \multirow{5}{*}{ Variables } & \multirow{5}{*}{ Prueba } & \multicolumn{4}{|c|}{ Seis a diez años } & \multicolumn{4}{|c|}{ Once a dieciséis años } \\
\hline & & \multirow{2}{*}{\multicolumn{8}{|c|}{$\begin{array}{l}\text { Falsas creencias de primer orden } \\
\text { Prueba superada }\end{array}$}} \\
\hline & & & & & & & & & \\
\hline & & \multicolumn{2}{|c|}{ No } & \multicolumn{2}{|c|}{ Sí } & \multicolumn{2}{|c|}{ No } & \multicolumn{2}{|c|}{ Sí } \\
\hline & & $\chi$ & D.S. & $\chi$ & D.S. & $\chi$ & D.S. & $\chi$ & D.S. \\
\hline \multirow{2}{*}{$\begin{array}{c}\text { Flexibilidad } \\
\text { cognitiva }\end{array}$} & Número de categorías & $1,63 *$ & 1,06 & 2,50 & 0,58 & $2,33 *$ & 0,58 & 2,40 & 1,52 \\
\hline & respuestas perseverativas & 9,38 & 13,72 & $5,50 *$ & 3,87 & 12,00 & 7,55 & $3,80 *$ & 2,17 \\
\hline \multirow{3}{*}{$\begin{array}{l}\text { Lenguaje } \\
\text { comprensivo }\end{array}$} & Semejanzas & $9,13 *$ & 3,64 & 10,00 & 1,41 & 13,33 & 4,51 & $11,00 *$ & 4,47 \\
\hline & Vocabulario & $9,25^{*}$ & 4,33 & 9,50 & 3,11 & 10,33 & 2,08 & $7,00 *$ & 2,83 \\
\hline & Comprensión & $5,88^{*}$ & 3,94 & 6,75 & 2,99 & 7,67 & 8,33 & $4,20 *$ & 2,77 \\
\hline $\begin{array}{l}\text { Lenguaje } \\
\text { expresivo }\end{array}$ & Coherencia narrativa & $4,50 *$ & 3,21 & 7,75 & 0,50 & $6,67 *$ & 1,15 & 7,20 & 1,10 \\
\hline
\end{tabular}

* Puntajes con bajo desempeño en las variables con relación a la prueba de teoría de la mente de primer orden Fuente: elaboración propia.

Relación entre variables flexibilidad cognitiva, lenguaje comprensivo y expresivo, por rangos de edad, respecto a la prueba de falsas creencias de segundo orden. Los resultados muestran que los participantes en el rango de seis a diez años que no aprobaron la prueba de falsas creencias de segundo orden tuvieron un mayor puntaje promedio en el número de categorías y un puntaje promedio menor en el número de respuestas perseverativas. Mientras tanto, en el grupo de once a dieciséis años, quienes no aprobaron la prueba de falsas creencias de segundo orden obtuvieron un mayor puntaje promedio tanto en el número de categorías como en el número de respuestas perseverativas.

En cuanto al lenguaje comprensivo, en ambos rangos de edad, quienes superaron la prueba de falsas creencias de segundo orden tuvieron un mayor puntaje promedio en las pruebas de semejanzas y comprensión, pero un puntaje promedio menor en la prueba de vocabulario.

Posteriormente se evaluó si existían diferencias estadísticamente significativas entre los grupos de edad, entre quienes aprobaron la prueba de falsas creencias de segundo orden y quienes no la aprobaron. También se evaluó si existían diferencias entre los que aprobaron o no la prueba, en cada uno de los rangos de edad. Para ello se aplicó la prueba $U$ de Mann-Whitney y se encontró que en ninguno de los casos examinados existieron diferencias estadísticamente significativas (Tabla 3). 
Tabla 3. Prueba Falsas creencias de segundo orden.

\begin{tabular}{|c|c|c|c|c|c|c|c|c|c|}
\hline \multirow{5}{*}{ Variables } & \multirow{5}{*}{ Prueba } & \multicolumn{4}{|c|}{ Seis a diez años } & \multicolumn{4}{|c|}{ Once a dieciséis años } \\
\hline & & \multirow{2}{*}{\multicolumn{8}{|c|}{$\begin{array}{c}\text { Falsas creencias de segundo orden } \\
\text { Prueba superada }\end{array}$}} \\
\hline & & & & & & & & & \\
\hline & & \multicolumn{2}{|c|}{ No } & \multicolumn{2}{|c|}{ Sí } & \multicolumn{2}{|c|}{ No } & \multicolumn{2}{|c|}{ Sí } \\
\hline & & $\chi$ & D.S. & $\chi$ & D.S. & $\chi$ & D.S. & $\chi$ & D.S. \\
\hline \multirow{2}{*}{$\begin{array}{l}\text { Flexibilidad } \\
\text { cognitiva }\end{array}$} & Número de categorías & 2,17 & 0,75 & $1,67 *$ & 1,21 & 2,67 & 1,15 & $2,20 *$ & 1,30 \\
\hline & respuestas perseverativas & $6,67 *$ & 3,39 & 9,50 & 16,26 & 7,00 & 5,29 & $6,80 *$ & 7,12 \\
\hline \multirow{3}{*}{$\begin{array}{c}\text { Lenguaje } \\
\text { comprensivo }\end{array}$} & Semejanzas & $8,83 *$ & 1,47 & 10,00 & 4,15 & $11,67 *$ & 2,52 & 12,00 & 5,43 \\
\hline & Vocabulario & 10,00 & 2,76 & $8,67 *$ & 4,84 & 8,33 & 0,58 & $8,20 *$ & 3,90 \\
\hline & Comprensión & $5,67 *$ & 2,88 & 6,67 & 4,32 & $3,33 *$ & 2,52 & 6,80 & 6,26 \\
\hline $\begin{array}{l}\text { Lenguaje } \\
\text { expresivo }\end{array}$ & Coherencia narrativa & 6,00 & 3,16 & $5,17 *$ & 3,13 & 7,33 & 1,15 & $6,80 *$ & 1,10 \\
\hline
\end{tabular}

* Puntajes con bajo desempeño en las variables con relación a la prueba de teoría de la mente de segundo orden

Fuente: elaboración propia

\section{DISCUSIÓN}

En relación con el desempeño y comprensión de la falsa creencia de primer y segundo orden, los resultados sugieren una menor habilidad en los participantes para identificar que alguien tiene una creencia equivocada (primer orden), resultado que concuerda con investigaciones como las de Baron-Cohen (2000) y Leslie (1987), centradas en autismo, las cuales indican que estos niños "tienen graves problemas para teorizar acerca de la mente de los demás". Allí también refieren que "Ios niños autistas no están preparados para atribuir estados mentales a otras personas" (Baron-Cohen, et al.,1985, citado en Echeverry, 2010).

En este sentido, otros estudios demuestran que el marcado déficit en las relaciones interpersonales ha sido abordado por el modelo teórico de ToM que postula que los sujetos con SA muestran serias dificultades para "ponerse en el lugar del otro" e intuir su mundo mental, afectando considerablemente su desempeño en el ámbito de las interacciones sociales (Baron-Cohen, 1996, citado en Serna Molpeceres, 2014). Por consiguiente, y como lo concluyen autores como Astington y Gopnik (1991), hay un atraso en la adquisición de la comprensión de la falsa creencia de primer orden, y en contraste con la literatura acerca de los inicios del desarrollo se dice que entre los cuatro y seis años existe un cambio significativo en la teoría de la mente marcado por la comprensión de la falsa creencia de primer orden; sin embargo, es llamativo que en el presente estudio dichas dificultades se siguieron presentando en el SA en edades más avanzadas. 
Asimismo, Artigas (2000), Martín-Borreguero (2005) y Martos-Pérez y Paula-Pérez (2011) evidenciaron que sujetos diagnosticados con SA presentan un retraso importante con las formas de modulación utilizadas para transmitir y clarificar las intenciones de los demás, observándose fallas en este proceso de aprendizaje de dichas reglas, lo que causa problemas con las intenciones comunicativas, las presuposiciones y el discurso, por lo que tienen que realizar un importante esfuerzo en las situaciones sociales (citado en Beltrán, Díaz y Zapata, 2016). Esto confirma la relación de los resultados de la presente investigación en cuanto al desempeño en la tarea falsas creencias de primer orden.

Sin embargo, en las investigaciones mencionadas, el análisis de los resultados por rangos de edad sugiere que en ambas pruebas el incremento de la edad favorece su aprobación. Esto permite concluir que, a pesar de presentar mayor dificultad en la tarea de primer orden, esto no fue impedimento para desempeñarse de manera positiva en la de segundo orden. Esto nos lleva a inferir la existencia de un déficit específico en la atribución de falsas creencias de primer orden, más no en la de segundo orden.

Dichos componentes se distancian de la investigación realizada por Serrano Ortiz (2012), en cuyo estudio realizado con niños con desarrollo normal, se encontró que "existe un desarrollo continuo en la comprensión de la mente, de manera que algunas comprensiones se adquieren antes que otras." Además, se asume que "la comprensión de la mente de primer orden se adquiere por completo en edades intermedias, especialmente entre los 6 y 8 años, después se superan las tareas más relacionadas con la compresión de segundo orden" Serrano Ortiz (2012). Es posible suponer entonces que para los casos de niños diagnosticados con SA el desarrollo de las habilidades evaluadas en las pruebas de falsas creencias de primer y segundo orden no es continuo, ya que como se mencionó anteriormente, en el presente estudio el desempeño en la prueba de segundo orden no depende de la de primer orden ni del rango de edad, y que probablemente esto sea por el entrenamiento que se crea a partir de la aplicación de las de primer orden independientemente de su desempeño en estas, se podría considerar que se induce una respuesta esperada en las pruebas de segundo orden por sospecha de la respuesta correcta, ya que son historias similares.

De otro lado es importante resaltar con respecto a la prueba de primer y segundo orden evaluada en un estudio de Orozco y Zuluaga (2015), sobre teoría de la mente en TDAH, que en esta tampoco fue impedimento el bajo desempeño en primer orden para obtener un resultado positivo en las de segundo orden. Además, se agrega la importancia del tratamiento, el apoyo de las instituciones educativas y la estimulación en dichas habilidades relacionadas con esta prueba y con la teorización de la mente para el resultado positivo en el desempeño de la prueba.

De otro lado y con respecto a la variable de flexibilidad cognitiva considerada en el presente estudio, los datos obtenidos en cuanto a su desempeño de acuerdo a la evaluación del número de respuestas perseverativas tuvieron un alto grado de variación por la presencia de puntuaciones atípicas en algunos de los participantes. Aquellos en el rango de once a dieciséis años obtuvieron un puntaje mayor al del grupo de seis a diez años en la prueba de número de categorías y un puntaje menor en el número de respuestas perseverativas. Esto sugiere que los participantes en el rango de edad más 
alto, tienen una mayor flexibilidad cognitiva que los de menor edad, y se observa un desarrollo continuo. Coincide esto con lo presentado por Riviére (2001) el hecho de que hablar (o no hablar, quien menciona con respecto a la flexibilidad cognitiva que "[...] desde edades tempranas (2-5 años), se construyen las funciones superiores, nutriendo el conocimiento y la experiencia. En estas etapas se desarrollan principalmente el lenguaje, la simbolización, las habilidades sociales y las capacidades mentalistas.

Con lo anterior se vuelve a confirmar lo que en otras investigaciones se evidencia acerca de la flexibilidad cognitiva, con respecto a la cual existe una relación directa con los procesos de maduración y los rangos de edad. Es llamativo que por el contrario en el presente estudio los resultados de teoría de la mente muestren un desempeño que no corresponde a procesos de maduración y rangos de edad, a pesar de que en investigaciones como las de Tirapu-Ustárroz, Pérez-Sayes, Erekatxo-Bilbao y PelegrínValero (2007) y Delgado y Etchepareborda (2013) se coincida en afirmar que la teoría de la mente y la flexibilidad cognitiva comparten algunos sustratos neuroanatómicos.

En lenguaje comprensivo y expresivo ambos grupos tuvieron un desempeño por debajo de la media. Se observaron los desempeños más deficientes en comprensión en ambos rangos de edad y en coherencia narrativa en el rango de edad de seis a diez años, sin embargo, en vocabulario y semejanzas su desempeño fue mejor en ambos rangos de edad. Esta aproximación concuerda con estudios como los de Martín-Borreguero (2005), quien define que en términos del procesamiento semántico y pragmático ha sido demostrado que los adolescentes y adultos con SA tienen un patrón atípico, al presentar mayor afectación en el desempeño de la semántica y la pragmática (citado en Beltrán, Díaz y Zapata, 2016).

Además, el mismo autor en sus estudios confirma la existencia de un patrón diferenciado en el SA que afecta la adquisición y el desarrollo de sus habilidades lingüísticas, esto relacionado con el presente estudio, en el que se arrojan resultados que definen que con respecto al lenguaje comprensivo no hay una continuidad relacionada con el proceso madurativo, mientras que en el lenguaje expresivo, el rango de edad sí influye en el desempeño de las habilidades lingüísticas, ya que en el rango de once a dieciséis años, los niños con SA obtuvieron un mejor desempeño.

Serrano Ortíz (2012), en su investigación con población con desarrollo típico evidencia que "a menor rendimiento en las tareas de lenguaje y de las funciones ejecutivas, menor desempeño en las tareas mentalistas."

En relación con el presente estudio y lo mencionado por Serrano Ortiz (2012), se observa que sí existen resultados relevantes relacionados con las variables propuestas y la influencia de estas en el desempeño de los niños con SA y su desarrollo madurativo, ya que a pesar de ser poblaciones diferentes, se observa que en el desarrollo de las habilidades mentalistas están implicados la flexibilidad cognitiva y el desarrollo del lenguaje. En el caso del presente estudio únicamente se presentó una relación madurativa en el lenguaje expresivo y la flexibilidad cognitiva, ya que por el contrario en el lenguaje comprensivo se obtuvo un desempeño bajo en ambos rangos de edad a pesar de presentar resultados positivos en vocabulario y semejanzas, lo cual clarifica que el proceso madurativo en este caso no tuvo mayor relevancia y en falsas creencias de primer orden no se evidenció un desarrollo continuo de dichos procesos. Se podría concluir entonces que a medida que avanza la edad se presenta mejor desempeño en las 
variables mencionadas, a excepción de la de lenguaje comprensivo, en la que el rango de edad no es determinante de su desempeño.

\section{CONCLUSIONES}

De acuerdo al análisis de resultados en las pruebas de flexibilidad cognitiva, lenguaje comprensivo y expresivo, por rangos de edad, se concluye que los niños con SA en el rango de edad de once a dieciséis años obtuvieron un puntaje promedio mayor que los participantes en el rango de seis a diez años en flexibilidad cognitiva, lo que sugiere una relación con los procesos de maduración. En teoría de la mente, los niños con SA tuvieron un mayor porcentaje de aciertos en la prueba falsas creencias de segundo orden, a pesar de presentar un porcentaje bajo de aciertos en la tarea de primer orden. Una explicación a dicho fenómeno proviene del entrenamiento que se crea a partir de la aplicación de la tarea de primer orden, independientemente de su desempeño en esta. Se puede considerar que tal entrenamiento induce una respuesta esperada en las pruebas de segundo orden por sospecha de la respuesta correcta, ya que son historias similares. Además, se agrega la influencia del tratamiento, el apoyo de las instituciones educativas y la estimulación en dichas habilidades relacionadas con esta prueba y con la teorización de la mente para el resultado positivo en el desempeño de la prueba.

Con respecto al lenguaje comprensivo, los niños con SA de seis a diez años obtuvieron puntajes promedios superiores a los niños de once a dieciséis en las pruebas de vocabulario y comprensión; sin embargo, en el lenguaje expresivo fueron los niños de once a dieciséis años los que obtuvieron un puntaje promedio mayor. Este comportamiento muestra que el lenguaje expresivo tiende a seguir el mismo ritmo del proceso madurativo, fenómeno que no se da en el lenguaje compresivo, habilidad donde se ponen en juego las relaciones sociales básicas, el poder utilizar las experiencias pasadas, incorporar normas de comportamiento, el juicio y el sentido común, aspectos que muestran alteración en esta población. Esto lleva a pensar que esta afectación se puede seguir presentando en edad avanzada, lo que sugiere que el compromiso pueda ser de corte estructural o neurobiológico.

Los niños con SA obtuvieron puntajes promedio inferiores en todas las variables, sin embargo, los resultados tanto en ToM de segundo orden como en flexibilidad cognitiva y lenguaje expresivo tienden a incrementarse en el rango de edad de once a dieciséis años, lo que evidencia que sigue permaneciendo la dificultad en el desempeño de lenguaje comprensivo y falsas creencias de primer orden en los niños con este trastorno. Lo anterior lleva a inferir que la comprensión y la expresión constituyen entonces un proceso complejo que va mucho más allá del lenguaje, ya que para ambas funciones se debe activar una serie de mecanismos procedentes del conocimiento no solo textual, sino también contextual; esto contribuye de manera significativa al lenguaje, la teoría de la mente como promotora de la interacción social y las funciones ejecutivas como encargadas de gran parte del desarrollo cognitivo implicado en el lenguaje.

\section{Limitaciones y consideraciones}

En el estudio se encontró como limitación el tamaño reducido de la muestra, que restringe la generalización de los resultados. Por lo tanto, para futuras investigaciones se recomienda ampliar la muestra para que esta sea más representativa en términos estadísticos. 
Se sugiere hacer un estudio longitudinal para evaluar a los niños en diferentes etapas de su vida y obtener información muy útil para inferir hipótesis y sacar conclusiones sobre la relación existente entre estas tres variables.

Se hace necesario realizar más estudios en población colombiana en edad escolar, con el fin de identificar aquellas condiciones latentes que pasan desapercibidas debido a los rasgos tan globales de las herramientas diagnósticas.

Finalmente se considera útil, no solamente en su aporte a la consolidación del conocimiento de dicho trastorno, sino que dichos hallazgos son un aporte a los profesionales del instituto DINA para la generación de posibles rutas de intervención, con la expectativa de generar una visibilización del trastorno en la sociedad y en las instituciones educativas, como una apuesta a los procesos de educación inclusiva.

\section{REFERENCIAS}

American Psychiatric Association (APA). (2002). Manual diagnóstico y estadístico de los trastornos mentales DSM-IV-TR. Washington.

Manual diagnóstico y estadístico de los trastornos mentales: DSM-5. Editorial medica panamericana, 2014.

Artigas, J. (2000). Aspectos neurocognitivos del síndrome de asperger. Neurologic Clinics, 34-44.

Asperger, H. (1944). Die "Autistischen Psychopathen" im Kindesalter. European Archives of Psychiatry and Clinical Neuroscience, 1(117), 76-136.

Astington, J.W. y Gopnik, A. (1991). Theoretical explanations of children's understanding of the mind. British Journal of Developmental Psychology, 9(1), 7-31.

Barragán, P.E. y Lozano, S.S. (2011). Identificación temprana de trastornos del lenguaje. Revista Médica Clínica Las Condes, 22(2), 227-232.

Baron-Cohen, S. (1996). Reading the mind in the face: A cross-cultural and developmental study. Visual Cognition, 3(1), 39-60.

Baron-Cohen, S. (2000). Theory of mind and autism: A fifteen year review. Understanding other minds: Perspectives from Developmental Cognitive Neuroscience, 2, 3-20.

Baron-Cohen, S., Leslie, A.M. y Frith, U. (1985). Does the autistic child have a "theory of mind"? Cognition, 21(1), 37-46.

Beltrán, C.; Díaz, L.A., y Zapata, M. (2016). Síndrome de Asperger: aspectos teóricos y prevalencia en dos ciudades de Colombia. Bucaramanga: Colciencias. P. UIS, Ed.

Berko, J. y Bernstein, N. (1999). Psicolingüística. Madrid: McGraw. 
Bloom, L. ; Lahey, M.; Hood, L. ; Lifter, K. y Fiess, K. (1980). Complex sentences: Acquisition of syntactic connectives and the semantic relations they encode. Journal of Child Language, $7(2), 235-261$.

Brunet, E.; Sarfati, Y.; Hardy-Bayle, M.; Decety, J. (2000). A PET investigation of the attribution of intentions with a noverbal task. Neuroimage, 11, 157-166.

Camila, P. (2008). La comprension de actos de habla directos e indirectos simples y complejos en niños con y sin asperger. Cyber Humanitatis, (45).

Carmona, M.B. (2001). Lenguaje y autismo: hacia una explicación ontogenética. En: Autismo: comprensión y explicación actual. Editores. Madrid: IMSERSO. 155-204.

Cassany, D. ; y Luna, M. y Sanz, G.(1994). Enseñar lengua. Bartzelona: Graó.

Cornago, A.; Navarro, M. y Collado, F. (2012). Manual de teoría de la mente para niños con autismo. Psylicom.

Corcoran, R. (1996). Exploring "theory of mind" in people with schizophrenia. Psychological Medicine, 26(3), 521-30.

Delgado, I.D. y Etchepareborda, M.C. (2013). Trastornos de las funciones ejecutivas. Diagnóstico y tratamiento. Revista de Neurología, 57(1), 95-103.

Duncan, J.; Burgess, P. y Emslie, H. (1995). Fluid intelligence after frontal lobe lesions. Neuropsychologia, 33(3), 261-268.

Echeverry, I.G. (2010). Ciencia Cognitiva, Teoría de la Mente y autismo. Pensamiento psicológico, 8(15).

Frith, C.D. (2004). Schizophrenia and theory of mind. Psychological Medicine, 34(3), 385389. doi: http://doi.org/10.1017/S0033291703001326

Frontera-Sancho, M. (2010). Funcionamiento cognitivo en síndrome de Asperger. Aspectos discapacitantes y Valoración. Recuperado de: http://www.asperger.es/publicaciones. php.

Gómez, L. y Peronard, M. (2005). El lenguaje humano. Léxico fundamental para la iniciación lingüística. Valparaíso.

Grande-García, I. (2012). Neurociencia social: una breve introducción al estudio de las bases neurobiológicas de la conducta social. Psicología y Ciencia Social, 11, 1-2.

Ibáñez, A. (2005). Autismo, funciones ejecutivas y mentalismo: Reconsiderando la heurística de descomposición modular. Revista Argentina de Neuropsicología, 6, 25-49.

Leslie, A.M. (1987). Pretense and representation: The origins of "theory of mind". Psychological Review, 94(4), 412.

Lezak, M.D. (1982). The problem of assessing executive functions. International Journal of Psychology, 17(1-4), 281-297. 
Martín-Borreguero, P. (2005). Perfil lingüístico del individuo con síndrome de Asperger: implicaciones para la investigación y la práctica clínica. Revista de Neurología, 41(1), 115-122.

Martos-Pérez, J. y Paula-Pérez, I. (2011). Una aproximación a las funciones ejecutivas en el trastorno del espectro autista. Revista de Neurología, 52(1), 147-153. Recuperado de: http://diposit.ub.edu/dspace/bitstream/2445/33383/1/587296.pdf\%5Cnhttp://www. centroenclave.es/documentos/autismoyFE.pdf

Milligan, K.; Astington, J. y Dack, L. (2007). Language and Theory of Mind: Meta-Analysis of the relation between language ability and false-belief understanding. Child Development. Child Development, 78(2), 622-646.

Ministerio de salud y protección social, instituto de evaluación tecnológica en salud. (2015). Protocolo clínico para el diagnóstico, tratamiento y ruta de atención integral de niños y niñas con trastornos del espectro autista. Recuperado de https://www.minsalud.gov.co/ sites/rid/Lists/BibliotecaDigital/RIDE/DE/CA/Protocolo-TEA-final.pdf

Orozco García, N. y Zuluaga Valencia, J.B. (2015). Teoría de la mente en niños y niñas con trastorno por Déficit de Atención con Hiperactividad "TDAH". Tesis Psicológica, 10(2), 136-148.

Ozonoff, S. y Miller, J.N. (1996). An exploration of right-hemisphere contributions to the pragmatic impairments of autism. Brain and Language, 52(3), 411-434.

Paynter, J. y Peterson, C. (2010). Language and ToM development in autism versus Asperger syndrome: Contrasting influences of syntactic versus lexical/semantic maturity. Research in Autism Spectrum Disorders, 4(3), 377-385. doi: http://doi.org/10.1016/j. rasd.2009.10.005

Premack, D. y Woodruff, G. (1978). Does the chimpanzee have a theory of mind? Behavioral and Brain Sciences, 1(3), 515-526.

Resches, M.; Serrat, E. ; Rostan, C. y Esteban, M. (2010). Lenguaje y Teoría de la Mente: una aproximación multidimensional. Infancia y aprendizaje, 33(3), 315-333.

Riviére, Á. (2001). Lenguaje y Autismo. Autismo: Enfoques Actuales para padres y profesionales de la salud y la educación, 17. Recuperado de: http://www.uca.edu.ar/uca/ common/grupo11/files/autismo-2013/DOCUMENTO-ARIVIERE-Lenguaje-y-autismo.pdf

Riviére, A. (2002). Inventario del espectro autista (IDEA). Buenos Aires: Fundec.

Rosselli, M.; Matute Villaseñor, E. ; Ardila Ardila, A.; Botero Gómez, V.E. ; Tangarife Salazar, G.A.; Echevarría Pulido, S.E. y Ocampo Agudelo, P. (2004). Neuropsychological Assessment of Children: a test battery for children between 5 and 16 years of age. A Colombian normative study. Revista de Neurologia, 38(8), 720-731.

Saalasti, S.; Lepistö, T.; Toppila, E. ; Kujala, T.; Laakso, M.; Nieminen-von Wendt, T. y JanssonVerkasalo, E. (2008). Language abilities of children with Asperger syndrome. Journal of Autism and Developmental Disorders, 38(8), 1574-1580. doi: http://doi.org/10.1007/ s10803-008-0540-3 
Sattler, J.M. (2003). Evaluación infantil: Aplicaciones cognitivas. (ed.). Manual Moderno.

Semrud-Clikeman, M.; Walkowiak, J.; Wilkinson, A. y Butcher, B. (2010). Executive functioning in children with asperger syndrome, ADHD-combined type, ADHD-predominately inattentive type, and controls. Journal of Autism and Developmental Disorders, 40(8), 1017-1027. doi: http://doi.org/10.1007/s10803-010-0951-9

Serna Molpeceres, S. (2014). Evaluación de la Teoría de la Mente en niños diagnosticados dentro del espectro Autista. Editor. Universidad de Valladolid. Facultad de Educación y Trabajo Social.

Serrano Ortiz, J. (2012). Desarrollo de la teoría de la mente, lenguaje y funciones ejecutivas en niños de 4 a 12 años. Recuperado de: http://hdl.handle.net/10803/123549

Siegal, M. y Varley, R. (2002). Neural sistems involved in "theory of mind". Nature Review, 3, 463-471.

Soprano, A.M. (2003). Evaluación de las funciones ejecutivas en el niño. Revista de Neurología, $37(1), 44-50$.

Tirapu-Ustárroz, J.; Pérez-Sayes, G.; Erekatxo-Bilbao, M. y Pelegrín-Valero, C. (2007). ¿Qué es la teoría de la mente? Revista de Neurologia, 44, 479-489.

Tirapu-Ustárroza, J. (2007). ¿Qué es la teoría de la mente? Revista Neurológica, 44(Teoría de la mente), 479-489. Recuperado de: http://www.uam.es/personal pdi/psicologia/cgil/ eto y neuro/Tirapu-Ustarroz 2007.pdf

Van Eylen, L.; Boets, B.; Steyaert, J.; Evers, K.; Wagemans, J. y Noens, I. (2011). Cognitive flexibility in autism spectrum disorder: Explaining the inconsistencies? Research in Autism Spectrum Disorders, 5(4), 1390-1401. doi: http://doi.org/10.1016/j.rasd.2011.01.025

Wechsler, D. (2005). Manual for The Wechsler Intelligence Scale for Children, Fourth Edition. San Antonio, Estados Unidos: The Psychological Corporation.

Wellman, H.M.; Cross, D. y Watson, J. (2001). Meta analysis of theory of mind development: the truth about false belief. Child Development, 72(3), 655-684.

Wimmer, H. y Perner, J. (1983). Beliefs about beliefs: Representation and constraining function of wrong beliefs in young children's understanding of deception. Cognition, 13, 103-128.

Yogeley, K. (2001). Mind reading. Neuroimage, 62, 89-106. 